\title{
Community integration: Current issues in cognitive and vocational rehabilitation for individuals with ABI
}

\author{
Paul Wehman, PhD; Tony Gentry, PhD, OTR/L; Michael West, PhD; ${ }^{*}$ Juan Carlos Arango-Lasprilla, PhD \\ Departments of Physical Medicine and Rehabilitation and Occupational Therapy, Virginia Commonwealth University, \\ Richmond, VA
}

\begin{abstract}
In this article, we examine cognitive and vocational rehabilitation and the issues related to minority veterans with acquired brain injury (ABI). As more servicemembers are returning from conflict, ways to help them repair their lives, not only physically but also socially and economically, are increasingly needed. The challenges of ABI are multifactorial; that is, the problems are not just cognitive or emotional but spill over into community living and vocational issues. Individuals from racial/ethnic minority backgrounds often face even more difficulties. Therefore, we review the nature of cognitive and vocational rehabilitation and suggest areas for additional research.
\end{abstract}

Key words: acquired brain injury, alternative work arrangements, cognitive rehabilitation, community integration, employer supports, posttraumatic stress disorder, race/ethnicity, return-towork, veterans, vocational rehabilitation.

\section{INTRODUCTION}

In this article, we examine the roles of cognitive and vocational rehabilitation and the issues related to individuals who are from minority backgrounds and have acquired brain injury (ABI). As more soldiers return from conflict, there has been increased attention focused on and an increased need for ways to help them repair their lives, not only physically but also socially and economically.

The challenges of ABI are multifactorial; that is, the problems are not just cognitive or emotional but spill over into community living and vocational issues and problems. Individuals from minority backgrounds often face even more difficulties. Therefore, we review the nature of cognitive and vocational rehabilitation and suggest areas for additional research.

\section{COGNITIVE REHABILITATION}

\section{Evidence for Effectiveness of Cognitive Rehabilitation}

The modern era of cognitive rehabilitation dates to Gianutsos's seminal article, "What is cognitive rehabilitation?” [1], which laid out an approach based on Russian psychologist Alexander Luria's theory of "cognitive processes" [2]. Gianutsos argued that it is possible to isolate and measure foundational aspects of cognition-attention, perception, and memory, among others-and treat them directly with the use of tabletop or computerized activities. Once these foundational abilities improved, everyday functioning was expected to improve, too. This paradigm, called "process-specific remediation," spread quickly.

Abbreviations: $\mathrm{ABI}=$ acquired brain injury, $\mathrm{CIQ}=\mathrm{Commu}-$ nity Integration Questionnaire, LOC $=$ loss of consciousness, PTSD = posttraumatic stress disorder, RTW = return-to-work, VA = Department of Veterans Affairs.

*Address all correspondence to Michael West, PhD; Rehabilitation Research and Training Center, Virginia Commonwealth University, PO Box 842011, Richmond, VA 23284; 804-828-5957; fax: 804-828-2193. Email: mdwest@vcu.edu DOI:10.1682/JRRD/2008.08.0105 
Schools of neuropsychology and speech therapy taught students how to measure and remediate cognitive processing deficits. At the same time, occupational therapists began to follow a compensatory approach, providing environmental modifications and assistive technology directed not at underlying cognitive processes but at helping an individual improve everyday functional performance despite cognitive impairment. For the past quarter century, these two models have shared the field, often within the same rehabilitation clinics. In a particular hospital, for instance, one might find a speech therapist utilizing process-specific training and an occupational therapist providing compensatory accommodations for the same patients.

Researchers have compared the remedial and compensatory treatment models. A National Institutes of Health consensus panel conducted a meta-analysis of cognitive rehabilitation research [3] and found significant improvement in health outcomes when a compensatory treatment model was used, especially when assistive technology for cognition (primarily reminder systems) was used. They also found that direct-training remediation efforts might lead to improvements on laboratory tests but that these improvements did not necessarily transfer to improved functional performance in everyday life. The consensus report added that future research into cognitive rehabilitation should focus primarily on whether therapy actually improved real-world outcomes for individuals with cognitive impairment.

A second comprehensive research meta-analysis largely concurred [4]. The findings in this study were followed up in 2006 to incorporate later research [5]. The authors found that (1) cognitive rehabilitation works best when conducted by a multidisciplinary team of professionals, starting soon after injury and continuing into the community after hospital discharge; (2) compensatory approaches improve functioning in everyday life, working best when the teaching of adaptive cognitive strategies is emphasized and offered within a naturalized context (including caregiver training and community followalong); (3) computerized reminder systems and organizational tools effectively manage memory deficits; (4) process-specific remedial training works sometimes (especially in treating attentional deficits) and with some people (especially those with mild impairments); (5) gains from computer-based remedial programs (and some other direct-training efforts) do not transfer to everyday life; (6) community-based therapy is at least as effective as inpatient rehabilitation; and (7) more research into the real- world efficacy of various treatment approaches is needed. These findings, it is fair to say, have not yet been incorporated into contemporary practice in any uniform way. Cognitive rehabilitation today continues to be diverse, with variations in practice occurring even within practice sites.

\section{Lessons from Related Fields}

The evolution of cognitive rehabilitation in the past decade has corresponded to a growing body of scientific evidence that appears to overthrow the conventional wisdom that injured brains do not heal beyond a brief window of "spontaneous recovery" in the early months after injury. Animal studies have revealed a relationship among enriched environments, dendritic growth, and recovery of lost function [6-8]; constraint-induced, forced-use movement therapy studies have shown functional gains in limb use by stroke patients years after injury [9]. Cognitive rehabilitation therapists have only begun to explore what these findings may mean for clinical practice. Intensive training regimes, focused on developing improved attention and working memory, appear to hold promise, especially for individuals with mild cognitive impairment [10 13]. We do not yet know whether this approach can improve other areas of cognitive functioning or help those with more severe impairment.

Some therapists are seeking answers outside the brain injury community, incorporating literature from the developmental disabilities and special education fields in their efforts to address these neuroscience findings. This literature promotes community-based-rather than clinicbased-practice focused on the utilization of social supports, cognitive strategies, and assistive technologies in solving a person's everyday life challenges. Ylvisaker and Feeney, drawing on practices in the special education community, promote a community-based "positive behavioral support" approach to brain injury therapy [14]. Their model incorporates training family caregivers, educators, and employers as support personnel; developing antecedent activities that promote productive behaviors; promoting self-awareness and goal setting; and utilizing assistive technologies such as reminder systems and task-sequencing cues. Gentiva is a private company that follows a similar approach in their Rehab Without Walls ${ }^{\circledR}$ brain injury franchises, which primarily operate in the western United States. Gentiva advertises improved functional recovery and lower costs using a multidisciplinary, communitybased model focused on improved performance in a person's everyday life tasks [15]. In Australia, a team led by 
neuropsychologist Jennie Ponsford has developed a community-based model that has been formally tested in a comparison study with clinic-based outpatient therapy. The community-based model was shown to be at least as effective in improving functional recovery as, and less expensive than, clinic-based treatment [16]. This approach is highly consistent with the suggested employment model of vocational intervention described in the next section.

Community-based treatment challenges therapists to reexamine habits, relying less on a traditional processspecific approach while beginning to see their clients holistically. If "everyday functioning in the real world" is adopted as the standard of rehabilitation success, then traditional assessment of discrete cognitive processes may prove incomplete. Traditional assessments, most of which were designed to discern lesion location, do not predict how people will behave outside the clinic [17-18]. A few tools that assess functional performance in everyday life are in use, but more are needed, especially as cognitive rehabilitation therapists are increasingly called on to predict long-term disability and return-to-work (RTW) potential.

Barriers - institutional, personal, professional, and otherwise- stand in the way of this emerging paradigm. In the United States, the most significant barrier is the short shrift given by third-party payers to cognitive rehabilitation. Because healthcare dollars are typically restricted to "medical healing" - and because people with cognitive impairment can seem to have an "invisible disability"-insurers are loathe to pay. The evidence plainly shows, however, that efforts by professionally trained therapists to improve functional performance are both effective and cost-effective. The cognitive rehabilitation community, however, must further delineate best practice, as informed by research, emerging technologies, and lessons from related fields.

In sum, increasing research and attention are clearly being given to cognitive rehabilitation. Yet widespread work and community-based applications appear to be limited. It appears that cognitive rehabilitation must be blended into functional and community-based activities to have value for each individual veteran. More is discussed on this in the "Recommendations" section (p. 914).

\section{RETURN-TO-WORK INTERVENTION STRATEGIES AND ISSUES}

Poor RTW outcomes for individuals sustaining significant ABI have been well documented, and a substantial body of research has attempted to identify predictors of successful RTW [18-19]. This research has typically focused on the symptoms and conditions of the individuals. Increasingly imperative is the examination of RTW as an interaction between the needs and motivations of the individuals with $\mathrm{ABI}$ and the supports available within vocational, social, and economic environments [20-21]. To that end, this section will describe the critical role of employment supports in successful RTW.

Vocational rehabilitation providers, including Vocational Rehabilitation and Employment Program Services counselors, typically offer a range of employment support services to help individuals with disabilities gain and maintain employment. The services provided in both the prephase (locating work opportunities, completing applications, interviewing, etc.) and postphase (getting to work on time, learning job skills, communicating on the job, etc.) will depend on each individual's desires, abilities, and support needs.

Some veterans may need only minimal intervention or support. For example, during the job search, the person may need information on where to locate employment leads and a critique of interviewing skills or, once employed, information about how to transfer the use of compensatory memory strategies from the home to the new work setting. Other individuals with more significant cognitive impairments may need more assistance. For example, one-to-one assistance may be needed to identify their vocational strengths and locate or negotiate a job. Once employed, they may need assistance on the job site to ensure performance is up to the employer's standards.

One vocational service option that offers individualized and intensive support services for gaining and maintaining employment is supported employment. Using this approach, the individual does not have to "get ready" to work. Instead, customized employment support is provided by a vocational rehabilitation professional, sometimes called a job coach or employment specialist [22-26].

The coach helps the individual with a disability identify his or her vocational abilities and explore potential workplace support needs. In addition, the coach contacts employers on the job seeker's behalf to discuss hiring needs and the job seeker's assets. Once the individual is employed, the coach offers the new employee assistance on the job. For example, additional skills training and instruction on the use of compensatory memory and other strategies may be provided on the job to help the new worker meet the employer's work performance expectations. 
As the new hire becomes proficient at work, the coach fades his or her full-time presence on the job site until he or she is no longer there daily. However, the coach maintains regular contact with both the employee and employer to provide or facilitate additional support as needed to promote job retention.

Studies show that persons with ABI who are referred to supported employment services successfully obtain and maintain employment. In the late 1980s, practical strategies to help people with ABI were just evolving and supported employment had been described by Wehman et al. in detail [27-28]. From 1990 to 2000, supported employment and other practical strategies to promote employment for individuals with ABI were coming into the mainstream. In the late 1990s, Chestnut et al. evaluated the effectiveness of rehabilitation throughout the recovery phases of ABI by reviewing more than 3,000 abstracts [29]. Results showed that to determine the effectiveness of rehabilitation intervention for persons with $\mathrm{ABI}$, research studies needed to use a standardized assessment protocol. Additionally, the strongest studies supported the effectiveness of early intervention, compensatory cognitive rehabilitation, and supported employment. The review also concluded that supported employment had not been replicated in other settings, so generalization of the approach for individuals with ABI remained untested.

Although promoted as a promising approach to RTW after ABI, supported employment remains underutilized for this population. A review of biennial Rehabilitation Service Administration 911 data from 1993 to 2001 indicated that the vocational rehabilitation system is serving increasing numbers of individuals with $\mathrm{ABI}$ with some success. However, the data indicate that only 10 percent were rehabilitated using supported employment [24].

A customized approach like supported employment can be helpful to anyone with a disability but is particularly useful for people with more severe disabilities like ABI. With this strategy, the type, level, and intensity of services and supports are adapted to each person's needs and, under some circumstances, involve extensive intervention $[22,24,26]$.

Sometimes, particularly if the person has a physical disability or slowed movements, assistive equipment or devices may be introduced to help the worker get the job done. Other times, a simple change in where the work is performed, like allowing the employee to move to a different workstation, may be useful. Sometimes a personal assistant may be needed on the job at certain times of day or for scheduled events. Personal support services on the job might include assistance with eating, going to the restroom, or taking notes during a meeting [30].

In summary, many individuals with $\mathrm{ABI}$ will need assistance with locating work and learning how to perform the job. Workplace supports must be individualized. In addition, although these examples were presented in isolation, the unique interplay and right combination of supports are often what lead to success at work [22,24]. The type, level, and intensity of support fluctuates from person to person depending on the newly hired employee's abilities, the job tasks, the work environment, and the existing workplace supports.

\section{MINORITY ISSUES AND VETERANS}

The U.S. racial/ethnic minority population is growing and expected to constitute as much as 45 percent of the nation's population by 2050 [31]. As the minority population in the United States grows and Congress offers incentives for noncitizen legal residents to join the Armed Forces [32], the number of minorities serving in the military is also predicted to increase. Currently, 64.1 percent of Active Duty members are white, while 17.8 percent are African American, 9.0 percent Hispanic, 4.3 percent Asian, 1.7 percent American Indian or Alaska Native, and 0.2 percent Native Hawaiian or other Pacific Islander [33]. Thus, minorities presently represent more than one-third of the Active Duty force, and this percentage has risen 6 percent since 1990, before the policy changes of the Bush administration.

Now and for the coming decades, larger proportions of veterans will be from racial/ethnic minority groups and more likely to return with an ABI from war-torn countries like Iraq and Afghanistan. However, equally important to recognize is that military personnel in both combat and noncombat posts are at high risk for sustaining an ABI [3436]. One study, for example, found that 23 percent of noncombat, Active Duty soldiers at Fort Bragg $(n=2,276)$ sustained an ABI during their military service [37]. The risk of ABI was highest among those soldiers with a prior ABI. Moreover, Hispanic and African-American veterans have been found to have higher rates of posttraumatic stress disorder (PTSD) than their white counterparts [38-39]. Secondary data analyses of the National Vietnam Veterans Readjustment Study indicate that rates of PTSD among Hispanic, African-American, and white veterans were 
27.9 percent, 20.6 percent, and 13.7 percent, respectively [40]. PTSD often complicates functional improvement, especially RTW and community integration, after ABI. Taken together, these statistics pose unique challenges for the rehabilitation and care of these individuals.

To date, very little is known about the influence of race/ethnicity on RTW and community integration after $\mathrm{ABI}$ in veterans. The effects of race/ethnicity on these outcomes have been explored in the population of ABI survivors as a whole, and these studies will be briefly reviewed. Specifically regarding veterans with ABI, only one study has been published in the literature. Vanderploeg et al. found that race/ethnicity, loss of consciousness (LOC), and current region of residence moderately predicted full-time work status, such that minorities with a history of LOC had significantly lower employment rates than whites in the Midwest, Northeast, and South regions of the United States [41]. No research is available on race/ethnicity and community integration in veterans with $\mathrm{ABI}$. In the following sections, brief overviews of the literature on race/ ethnicity and employment after ABI and race/ethnicity and community integration after ABI are provided.

\section{Return-to-Work after ABI}

According to the Department of Labor, approximately 4 percent of adult men and women in the United States were unemployed as of October 2007 [42]. When broken down by race/ethnicity, unemployment rates were higher among African Americans and Hispanics than whites $(8.5 \%$ and $5.6 \%$ vs $4.2 \%$, respectively). The unemployment rate for Asians in the general population was less than that of whites (3.7\% vs $4.2 \%$, respectively). Unemployment rates are higher for minority individuals who have experienced an ABI, with some studies reporting unemployment rates as high as 69 percent [43]. Because of the high incidence of ABI in racially and ethnically diverse communities and an increase in minority ABI survivors, recent attention has been given to the role of race/ethnicity on RTW after ABI.

Current knowledge of the influence of race/ethnicity on RTW after ABI is derived from nationwide databases such as the ABI Model Systems National Database. These studies examine employment status at 1 year postinjury, productivity (at least part-time employment, student status, or full-time homemaker), or job stability (maintaining competitive employment at various follow-up periods for as long as 4 years postinjury). In general, these studies have found that race/ethnicity independently predicts employ- ment outcomes after ABI. Sherer et al. found that African Americans were twice $(0.34,0.73)$ as likely as whites to be nonproductive at 1 year postinjury, controlling for preinjury productivity, education, and cause of injury [44]. ArangoLasprilla et al. found that minorities as a group (including African Americans, Hispanics, Asians, and American Indians) were 2.17 times $(1.78,2.66)$ more likely than whites to not be competitively employed at 1 year postinjury, after adjusting for employment status at admission, sex, Disability Rating Scale at discharge, marital status, cause of injury, age, and education [45]. Kreutzer et al. found that minorities were less likely than whites to be stably employed over the 4 years following ABI [46]. Arango-Lasprilla et al. found that, compared with whites, minorities were 4.92 times $(2.468,9.792)$ more likely to be unemployed versus stably employed, 2.37 times $(1.400,4.011)$ more likely to be unemployed versus unstably employed, and 2.08 times $(1.042,4.131)$ more likely to be unstably employed versus stably employed [47].

\section{Community Integration after ABI}

After an ABI, one of the most important objectives is to maximize the survivor's level of reintegration into the community and return to productive activity [48]. However, the cognitive, emotional, psychosocial, and physical impairments associated with ABI often limit some individuals' ability to return to productive activity, whether it is work, school, or other endeavors [49].

As with studies on RTW after ABI, research on race/ ethnicity and community integration after $\mathrm{ABI}$ has been conducted using the ABI Model Systems National Database. In general, these studies suggest that race/ethnicity independently predicts community integration 1 year after ABI. Hart et al. found that even though white and African-American ABI survivors had similar demographic characteristics, African Americans scored significantly lower on the Social Integration subscale of the Community Integration Questionnaire (CIQ) [50]. Compared with white ABI survivors, Hispanic ABI survivors had poorer community integration (lower CIQ scores), after controlling for age, length of posttraumatic amnesia, injury severity, Disability Rating Scale at admission, Functional Independence Measure at admission, and preinjury educational levels. Rosenthal et al. found that, compared with whites, African-American and Hispanic ABI survivors as a group had lower levels of community integration at 1 year postinjury, controlling for etiology, injury severity, age, sex, and functional status at discharge 
[43]. Arango-Lasprilla et al. increased the sample size of the Rosenthal et al. study by incorporating individuals from more ABI Model Systems Centers and found that African-American and Hispanic ABI survivors had poorer community integration at 1 year postinjury than whites, after controlling for length of posttraumatic amnesia, injury severity, preinjury educational level, cause of injury, preinjury employment, and preinjury marital status [51]. Hispanic ABI survivors as a group had poorer community integration than white survivors, despite similar functional status at inpatient rehabilitation discharge and independent of age, length of posttraumatic amnesia, injury severity, and preinjury educational levels [52].

In summary, numerous studies have shown that race/ ethnicity is a significant predictor of RTW and community integration after ABI, after various sociodemographic, injury characteristics, and postinjury functional status variables are taken into account. Various factors associated with race/ethnicity, such as religious beliefs, family roles, language proficiency, and immigration status, may have an important influence on RTW and community integration after $\mathrm{ABI}$; however, further research is needed to identify such modifying variables. Such research might help determine populations at higher risk of lower rates of RTW and/or poorer community integration. Furthermore, investigations would be expected to guide the development of specialized rehabilitation programs targeted to the needs of minority populations.

\section{RECOMMENDATIONS}

\section{Cognitive Rehabilitation}

Cognitive rehabilitation is a relatively new and rapidly expanding field that incorporates findings from neuroscientists, neurologists, multidisciplinary rehabilitation clinicians, special educators, and assistive technologists, among others. The Department of Veterans Affairs (VA) is uniquely positioned to play a vital role in exploring and implementing assessment and treatment approaches that synthesize findings from these disparate fields, translating science to practice. Recommendations include the following:

1. Clinicians need to recognize the interdisciplinary and pervasive nature of cognitive disability and collaborate to develop a holistic cognitive rehabilitation model.

2. Clinicians involved in cognitive rehabilitation need to be trained to conduct prospective outcomes-based research and be provided with supports to conduct such research.

3. Cognitive rehabilitation assessment tools that measure and predict functional performance in everyday life are sorely needed. Researchers need to develop and validate instruments that accurately measure changes in discrete cognitive processes that discriminate between impairments caused by brain injury and comorbidities and that track globally improved functioning in the community.

4. Models for community-based cognitive rehabilitation need to be developed and tested within the VA system, with a focus on functional independence in real-world settings. Promising approaches include the use of positive behavioral supports, supported employment, and assistive technology for cognition.

5. Building upon recent research into direct-training interventions, models for intensive training of underlying cognitive processes need to be developed and tested to determine how best to leverage the potential for cortical plasticity after injury.

6. Researchers need to consider the following questions: (1) Which populations within the VA catchment are most appropriate for these approaches? (2) How do comorbidities such as depression and PTSD affect cognitive rehabilitation results? (3) How can a directtraining model be integrated with a community-based treatment paradigm? and (4) Is there long-term carryover of rehabilitation benefits?

7. The VA needs to develop a streamlined method for disseminating research findings and incorporating proven treatment models systemwide.

\section{Return-to-Work}

A number of areas for future research, policy, and employment practices need to be considered to improve work outcomes for persons with ABI. We view several of the following points as leading areas for consideration:

1. More evidence-based prospective studies are needed to compare the efficacy of different interventions on the work outcomes of persons with $\mathrm{ABI}$, much in the same vein as the growing body of literature on evidence-based practices with persons with severe mental illness. To date, the evidence regarding rehabilitation, including cognitive rehabilitation and vocational interventions, for individuals with ABI has largely consisted of case reports, case control studies, and cohort studies. Few randomized controlled trials of rehabilitation models, which would provide strong clinical evidence of effectiveness, have 
been conducted [53]. For example, studies that compare the outcomes of supported employment versus competitive employment without job-coach supports would be helpful. Also needed are studies that look at whether and when the time of intervention postacute makes a difference in the outcome.

2. The supported employment model has been described in much detail. Although the model is promoted as an innovative and promising approach to assisting individuals with severe disabilities with RTW, finding replication efforts or evidence that the approach is being utilized on a wide-scale basis by individuals with ABI remains difficult. Vocational rehabilitation and supported employment providers need access to education and resources that will prepare them to offer the service to this underserved group.

3. To improve access, information about possible RTW services should be provided to individuals with ABI and family members early in the postacute recovery stage. Efforts aimed at earlier intervention may promote a return to preinjury employment in the same or new position for some individuals.

4. Vocational rehabilitation professionals must embrace the basic principle of RTW services: everyone is employable when provided with the right type, level, and intensity of support and when efforts are made to help them locate workplaces and positions in which they will be valued and accommodated. This principle requires staff to be familiar with negotiating work opportunities with business owners and human resource staff.

In addition, those charged with overseeing RTW efforts must view employment as a process rather than an event. Thus, an involuntary termination from employment should not be viewed as a failure on the part of the employee. Instead, individuals with ABI should be given multiple opportunities as needed to return to employment. This approach should help them increase selfawareness and potentially job tenure by learning from these past experiences.

5. Finally, we recommend that self-employment, telework, temporary staffing, and independent contracting work arrangements be developed and that models be applied that go beyond traditional employment. These alternative work arrangements are becoming increasingly prevalent in the workforce and offer advantages and opportunities for many individuals with ABI and other serious disabilities.

\section{Minority Issues and Veterans}

Whether the racial/ethnic disparities in RTW and community integration after $\mathrm{ABI}$ in the general population of $\mathrm{ABI}$ survivors also exist in veterans is unclear. One might argue that such disparities are not as apparent because all military personnel receive free, universal healthcare both before and after their injury. However, previous research identifying the relationship between race/ethnicity and functional outcomes has used a relatively homogenous population of ABI survivors who received standardized, state-of-the-art care at a Model Systems Center. Although there may be reason to believe that findings of racial/ethnic disparities in RTW and community integration extend to the veteran population, this determination is not so clear cut in the area of community integration. Measurement of RTW is slightly more objective: an ABI survivor is either working $\mathrm{X}$ number of hours a week and earning a wage for the work (e.g., competitively employed) or he or she is not. Community integration tends to be more subjective, and the construct itself may include inherent cultural bias. To date, studies of community integration have used the CIQ, a questionnaire developed and validated in samples of white ABI survivors. Whether the observed racial/ethnic disparities in this outcome are true or simply reflect an inaccurate measurement tool warrants further attention. Culturally specific measures of community integration in veterans will be necessary to advance research on improving outcomes and quality of life in veterans with $\mathrm{ABI}$.

Furthermore, the previous research in the general population of $A B I$ survivors suggests that research on veterans with $A B I$ should have the following agenda:

1. To determine the incidence and prevalence of $A B I$ in noncombat and combat positions in the military and specify the potential differential rates of ABI across service branches and minority groups within each branch.

2. To confirm the existence of racial/ethnic disparities in RTW and community integration after ABI in combat and noncombat veterans.

3 . To examine the role of factors that may modify the relationship between race/ethnicity and functional outcomes (e.g., attitudes and beliefs, family and gender roles, religion/spirituality, expectations, immigration-related variables, socioeconomic status).

4. To identify the race/ethnicity-specific rehabilitation needs of veteran $\mathrm{ABI}$ survivors and their families. 


\section{CONCLUSIONS}

This article has examined cognitive and vocational rehabilitation and the issues related to veterans with $\mathrm{ABI}$. As more servicemembers are returning from conflict, interventions are needed to help them return to productivity, including compensatory strategies, job accommodations, and job coaching. Individuals from racial/ethnic minority backgrounds often face even more difficulties in returning to productivity and normalcy. One key to successful RTW is a the belief on the part of service providers that everyone, regardless of disability, is employable when provided with the right type, level, and intensity of support and when efforts are made to help them locate workplaces and positions in which their skills and presence will be valued and their limitations accommodated.

\section{ACKNOWLEDGMENTS}

\section{Author Contributions:}

Drafting of manuscript: P. Wehman, T. Gentry, M. West, J. C. ArangoLasprilla.

Financial Disclosures: The authors have declared that no competing interests exist.

Funding/Support: This material was based on work partially supported by the Virginia Commonwealth University Rehabilitation Research and Training Center (grant H133B040011).

\section{REFERENCES}

1. Gianutsos R. What is cognitive rehabilitation? J Rehabil. 1980;46(3):36-40. [PMID: 7401089]

2. Luria AR. Restoration of function after brain injury. Oxford (UK): Pergamon; 1963.

3. Rehabilitation of persons with traumatic brain injury. NIH Consens Statement. 1998;16(1):1-41. [PMID: 10874909]

4. Cicerone KD, Dahlberg C, Kalmar K, Langenbahn DM, Malec JF, Bergquist TF, Felicetti T, Giacino JT, Harley JP, Harrington DE, Herzog J, Kneipp S, Laatsch L, Morse PA. Evidence-based cognitive rehabilitation: Recommendations for clinical practice. Arch Phys Med Rehabil. 2000;81(12): 1596-1615. [PMID: 11128897]

DOI:10.1053/apmr.2000.19240

5. Cicerone KD. Cognitive rehabilitation. In: Zasler ND, Katz DI, Zafonte RD, editors. Brain injury medicine: Principles and practice. New York (NY): Demos; 2007. p. 765-77.

6. Johansson BB. Functional outcomes in rats transferred to an enriched environment 15 days after focal brain ischemia. Stroke. 1996;27(2):324-26. [PMID: 8571431]
7. Johansson BB, Ohlsson AL. Environment, social interaction, and physical activity as determinants of functional outcome after cerebral infarction in the rat. Exp Neurol. 1996;139(2):322-27. [PMID: 8654535]

DOI:10.1006/exnr.1996.0106

8. Leggio MG, Mandolesi L, Federico F, Spirito F, Ricci B, Gelfo F, Petrosini L. Environmental enrichment promotes improved spatial abilities and enhanced dendritic growth in the rat. Behav Brain Res. 2005;163(1):78-90. [PMID: 15913801] DOI:10.1016/j.bbr.2005.04.009

9. Liepert J, Miltner WH, Bauder H, Sommer M, Dettmers C, Taub E, Weiller C. Motor cortex plasticity during constraint-induced movement therapy in stroke patients. Neurosci Lett. 1998;250(1):5-8. [PMID: 9696052] DOI:10.1016/S0304-3940(98)00386-3

10. Hooft IH. Cognitive rehabilitation in children with acquired brain injuries [dissertation]. Stockholm (Sweden): Karolinska University; 2005.

11. Olesen PJ, Westerberg H, Klingberg T. Increased prefrontal and parietal activity after training of working memory. Nat Neurosci. 2004;7(1):75-79. [PMID: 14699419] DOI:10.1038/nn1165

12. Klingberg T, Fernell E, Olesen PJ, Johnson M, Gustafsson P, Dahlström K, Gillberg CG, Forssberg H, Westerberg H. Computerized training of working memory in children with ADHD — A randomized, controlled trial. J Am Acad Child Adolesc Psychiatry. 2005;44(2):177-86. [PMID: 15689731] DOI:10.1097/00004583-200502000-00010

13. Buonomano DV, Merzenich MM. Cortical plasticity: From synapses to maps. Annu Rev Neurosci. 1998;21:149-86. [PMID: 9530495] DOI:10.1146/annurev.neuro.21.1.149

14. Ylvisaker M, Feeney TJ. Collaborative brain injury intervention: Positive everyday routines. San Diego (CA): Singular; 1998.

15. Rehab Without Walls [Internet]. Atlanta (GA): Gentiva Health Care. [cited 2007 Dec 4] Available from: http://www.gentiva.com/services/GentivaRehabWithoutWalls/default.asp/.

16. Ponsford J, Harrington H, Olver J, Roper M. Evaluation of a community-based model of rehabilitation following traumatic brain injury. Neuropsychol Rehabil. 2006;16(3):315-28. [PMID: 16835154] DOI:10.1080/09602010500176534

17. Chaytor N, Schmitter-Edgecombe M. The ecological validity of neuropsychological tests: A review of the literature on everyday cognitive skills. Neuropsychol Rev. 2003;13(4): 181-97. [PMID: 15000225] DOI:10.1023/B:NERV.0000009483.91468.fb

18. Sbordonne RJ, Long CJ. Ecological validity of neuropsychological testing. Boca Raton (FL): St. Lucie Press; 1998. 
19. McCrimmon S, Oddy M. Return to work following moderate-to-severe traumatic brain injury. Brain Inj. 2006;20(10): 1037-46. [PMID: 17060136] DOI:10.1080/02699050600909656

20. Kowalske K, Plenger P, Lusby B, Hayden ME. Vocational reentry following ABI: An enablement model. J Head Trauma Rehabil. 2000;15(4):989-99. DOI:10.1097/00001199-200008000-00003

21. Ruffalo CF, Friedland JF, Dawson DR, Colantonio A, Lindsay PH. Mild traumatic brain injury from motor vehicle accidents: Factors associated with return to work. Arch Phys Med Rehabil. 1999;80(4):392-98. [PMID: 10206600] DOI:10.1016/S0003-9993(99)90275-7

22. Wehman P, Booth M, Stallard D, Mundy A, Sherron P, West M, Cifu D. Return to work for persons with traumatic brain injury and spinal cord injury: Three case studies. Int $\mathbf{J}$ Rehabil Res. 1994;17(3):268-77. [PMID: 8002134] DOI:10.1097/00004356-199409000-00008

23. Wehman P, Kregel J, Keyser-Marcus L, Sherron-Targett P, Campbell L, West M, Cifu DX. Supported employment for persons with traumatic brain injury: A preliminary investigation of long-term follow-up costs and program efficiency. Arch Phys Med Rehabil. 2005;84(2):192-96.

[PMID: 12601649]

DOI:10.1053/apmr.2003.50027

24. Wehman P, Targett P, West M, Kregel J. Productive work and employment for persons with traumatic brain injury: What have we learned after 20 years? J Head Trauma Rehabil. 2005:20(2):115-27. [PMID: 15803036] DOI:10.1097/00001199-200503000-00001

25. Wehman PH, West MD, Kregel J, Sherron P, Kreutzer J. Return to work for persons with severe traumatic brain injury: A data-based approach to program development. J Head Trauma Rehabil. 1995;10:(1):27-39. DOI:10.1097/00001199-199502000-00005

26. Yasuda S, Wehman P, Targett P, Cifu D, West M. Return to work for persons with traumatic brain injury. Am J Phys Med Rehabil. 2001;80(11):852-64. [PMID: 11805460] DOI:10.1097/00002060-200111000-00011

27. Wehman P, Kreutzer J, Sale P, West M, Morton MV, Diambra J. Cognitive impairment and remediation: Implications for employment following traumatic brain injury. J Head Trauma Rehabil. 1989;4(3):66-75.

DOI:10.1097/00001199-198909000-00010

28. Wehman P, Kreutzer J, West M, Sherron P, Diambra J, Fry R, Groah C, Sale P, Killam S. Employment outcomes of persons following traumatic brain injury: Pre-injury, postinjury and supported employment. Brain Inj. 1989;3(4): 397-12. [PMID: 2819319]

DOI:10.3109/02699058909004563

29. Chesnut RM, Carney N, Maynard H, Mann NC, Patterson P, Helfand M. Summary report: Evidence for the effective- ness of rehabilitation for persons with traumatic brain injury. J Head Trauma Rehabil. 1999;14(2):176-88.

[PMID: 10191375]

DOI:10.1097/00001199-199904000-00007

30. Targett P, Wehman P, Young C. Return to work for persons with spinal cord injury: Designing work supports. NeuroRehabilitation. 2004;19(2):131-39. [PMID: 15201472]

31. Bergman M. More diversity, slower growth [Internet]. Washington (DC): U.S. Census Bureau News; 2004 Mar 18. [cited 2007 Oct 15]. Available from: http://www.census.gov/PressRelease/www/releases/archives/population/001720.html/.

32. Editorial Board. Congress to immigrants: Dream on [Internet]. New York (NY): New York Times; 2007 Oct 25. [cited 2007 Dec 3]. Available from: http://theboard.blogs.nytimes.com/ 2007/10/25/congress-to-immigrants-dream-on/.

33. U.S. Department of Defense. 2005 demographics report. Washington (DC): Office of the Deputy Under Secretary of Defense (Military Community and Family Policy); 2005. [cited 2007 Sept 12]. Available from: http://militaryhomefront.dod.mil/.

34. Ommaya AK, Ommaya AK, Dannenberg AL, Salazar AM. Causation, incidence, and costs of traumatic brain injury in the U.S. military medical system. J Trauma. 1996;40(2): 211-17. [PMID: 8637068]

DOI:10.1097/00005373-199602000-00007

35. Lew HL, Poole JH, Alavrez S, Moore W. Soldiers with occult traumatic brain injury. Am J Phys Med Rehabil. 2005;84(6):393-98. [PMID: 15905652] DOI:10.1097/01.phm.0000163703.91647.a7

36. Okie S. Traumatic brain injury in the war zone. N Engl J Med. 2005;352(20):2043-47. [PMID: 15901856] DOI:10.1056/NEJMp058102

37. Ivins BJ, Schwab KA, Warden D, Harvey TL, Hoilien MA, Powell CO, Johnson CS, Salazar AM. Traumatic brain injury in U.S. Army paratroopers: Prevalence and character. J Trauma. 2003;55(4):617-21. [PMID: 14566111] DOI:10.1097/01.TA.0000052368.97573.D4

38. Ortega AN, Rosenheck R. Posttraumatic stress disorder among Hispanic Vietnam veterans. Am J Psychiatry. 2000; 157(4):615-19. [PMID: 10739422] DOI:10.1176/appi.ajp.157.4.615

39. Schlenger WE, Kulka RA, Fairbank JA, Hough RL, Jordan BK, Marmar CR, Weiss DS. The prevalence of post-traumatic stress disorder in the Vietnam generation: A multimethod, multisource assessment of psychiatric disorder. J Trauma Stress. 1992;5(3):333-63. DOI:10.1002/jts.2490050303

40. Kulka RA, Schlenger WE, Fairbank JA, Hough RL, Jordan BK, Marmar CR, Weiss DS, Grady DA, Cranston A. Trauma and the Vietnam war generation: Report of findings from the National Vietnam Veterans Readjustment Study. New York (NY): Brunner/Mazel; 1990. 
41. Vanderploeg RD, Curtiss G, Duchnick JJ, Luis CA. Demographic, medical, and psychiatric factors in work and marital status after mild head injury. J Head Trauma Rehabil. 2003;18(2):148-63. [PMID: 12802224] DOI:10.1097/00001199-200303000-00006

42. U.S. Department of Labor. The employment situation: October 2007. Washington (DC): Department of Labor; 2007. 30 p. Report No.: USDL 07-1678.

43. Rosenthal M, Dijkers M, Harrison-Felix C, Nabors N, Witol A, Young ME, Englander JS. Impact of minority status on functional outcome and community integration after traumatic brain injury. J Head Trauma Rehabil. 1996; 11(5):40-57. DOI:10.1097/00001199-199610000-00005

44. Sherer M, Sander AM, Nick TG, High WM Jr, Malec JF, Rosenthal M. Early cognitive status and productivity outcome after traumatic brain injury: Findings from the TBI model systems. Arch Phys Med Rehabil. 2002;83(2):183-92. [PMID: 11833021] DOI:10.1053/apmr.2002.28802

45. Arango-Lasprilla JC, Ketchum JM, Williams K, Kreutzer JS, Marquez de la Plata CD, O’Neil-Pirozzi TM, Wehman P. Racial differences in employment outcomes after traumatic brain injury. Arch Phys Med Rehabil. 2008;89(5):988-95. [PMID: 18452750] DOI:10.1016/j.apmr.2008.02.012

46. Kreutzer JS, Marwitz JH, Walker W, Sander A, Sherer M, Bogner J, Fraser R, Bushnik T. Moderating factors in return to work and job stability after traumatic brain injury. J Head Trauma Rehabil. 2003;18(2):128-38. [PMID: 12802222] DOI:10.1097/00001199-200303000-00004

47. Arango-Lasprilla JC, Ketchum JM, Gary KW, Kreutzer JS, O’Neil-Pirozzi TM, Wehman P, Marquez de la Plata C, Jha A. The influence of minority status on job stability after traumatic brain injury. PM R. 2009;1(1)41-49. [PMID: 19627871]
48. Rosenthal M, Ricker J. Traumatic brain injury. In: Frank RG, Elliott TR, editors. Handbook of rehabilitation psychology. Washington (DC): American Psychological Association; 2000. p. 49-74. DOI:10.1037/10361-003

49. Buffington AL, Malec JF. The vocational rehabilitation continuum: Maximizing outcomes through bridging the gap from hospital to community-based services. J Head Trauma Rehabil. 1997;12(5):1-13. DOI:10.1097/00001199-199710000-00002

50. Hart T, Whyte J, Polansky M, Kersey-Matusiak G, FidlerSheppard R. Community outcomes following traumatic brain injury: Impact of race and preinjury status. J Head Trauma Rehabil. 2005;20(2):158-72. [PMID: 15803039] DOI:10.1097/00001199-200503000-00004

51. Arango-Lasprilla JC, Rosenthal M, Deluca J, Cifu DX, Hanks R, Komaroff E. Functional outcomes from inpatient rehabilitation after traumatic brain injury: How do Hispanics fare? Arch Phys Med Rehabil. 2007;88(1):11-18.

[PMID: 17207669] DOI:10.1016/j.apmr.2006.10.029

52. Arango-Lasprilla JC, Rosenthal M, Deluca J, Komaroff E, Sherer M, Cifu D, Hanks R. Traumatic brain injury and functional outcomes: Does minority status matter? Brain Inj. 2007;21(7):701-8. [PMID: 17653944] DOI:10.1080/02699050701481597

53. Turner-Stokes L, Disler PB, Nair A, Wade DT. Multidisciplinary rehabilitation for acquired brain injury in adults of working age. Cochrane Database Syst Rev. 2005; (3):CD004170. [PMID: 16034923]

Submitted for publication August 20, 2008. Accepted in revised form March 26, 2009. 